Sadler, D. R. (2011). Academic freedom, achievement standards and professional identity, Quality in Higher Education, 17: 85-100.

DOI: 10.1080/13538322.2011.554639

\title{
Academic freedom, achievement standards and professional identity
}

D Royce Sadler, Griffith Institute for Higher Education, Griffith University

\begin{abstract}
The tension between the freedom of academics to grade the achievements of their students without interference or coercion and the prerogative of higher education institutions to control grading standards is often deliberated by weighing up the authority and rights of the two parties. An alternative approach is to start with an analysis of the characteristics necessary for a system to exhibit integrity in grading academic achievement, and treat the establishment and maintenance of academic standards as a problem to be solved. This would allow the respective responsibilities of academics and institutions to be resolved within a concrete setting rather than in the abstract. Connecting the typical characteristics of a profession with Isaiah Berlin's two concepts of liberty leads to a productive partnership in which the respective interests of individual academics and the values of institutions can converge on a practical solution to the problem of academic freedom.
\end{abstract}

Keywords: academic freedom, academic standards, identity, peer review, professionalism

\section{Introduction}

Overt tension exists in a number of jurisdictions between academics, on the one hand, who regard it as their responsibility to assess and grade student achievement without external interference and, on the other hand, institutional administrations or independent agencies which regard it as their responsibility to monitor and regulate academic standards as necessary. The latter assert their rights by way of positional authority (in the case of institutional administrations) or formal delegation (in the case of quality assurance or similarly constituted agencies). The exercise of their rights is undertaken in order to maintain institutional reputations, to protect the value of academic qualifications, and more generally to be accountable to society at large.

This tension manifests itself when a grade assigned by an academic is changed by an institution's administration, or the academic is pressured to change it, for reasons 
that are extraneous to the actual level of a student's academic performance. Internationally, perspectives on the location of responsibility and authority vary widely, different positions being advocated and defended strongly on behalf of their respective constituencies. The responsibility for determining grades is typically discussed in the context of rights - the rights of academics as autonomous individuals and the rights of institutions or agencies which see their role as working to a wider agenda. For these reasons, and given the variety of national viewpoints and traditions as an overlay, it is unlikely that any potential solution would suit different systems equally well.

When there is no perceived problem, or when there are no allegations outstanding, clashes of authority are rare. Situational characteristics that bring the tension to the fore include: expressed doubts about the effectiveness of existing quality assurance processes, and complaints from academics about unreasonable institutional expectations brought about by structural changes which have taken place in higher education over the past few decades. The latter include: higher participation rates accompanied by less stringent entry requirements; greater competition among institutions for domestic and international student enrolments; and funding mechanisms in which income from public sources is tied to quantitative outputs such as levels of student retention and graduation. Clearly, the mobility of students and professional practitioners also benefits from having grades, degrees and qualifications that are comparable not only across institutions but also across provincial and national boundaries. Addressing the core problem and the tension it creates is difficult. One of the confounding factors is the technical complexity of obtaining hard evidence about the existing state of affairs, particularly with respect to allegations of grade inflation (Hunt 2008). At an even more basic level, the question of what exactly is meant by 'academic achievement standards' is seldom asked, let alone answered.

Attempts to resolve the issue of rights can take an abstract theoretical line, with individual academic rights put up against institutional (or in some countries state) rights. The alternative introduced in this article is goal-oriented. The strategy is to identify the nature of the assessment and grading problem to be solved and then to conceptualise and design a system which could produce at least a credible solution to the problem. This allows the rights-authority resolution to fall where it will. Before getting to that, it is useful first to clarify the scope and setting for this attempt, and then to analyse two articles which reflect quite different perspectives on the issue.

\section{Scope}

In this article, the term 'course' refers to a unit of study which forms the basic component of a degree 'program', often being taught over a fixed period of time such as one semester. The course grade records academic achievement on each student's academic transcript in the form of a compact verbal descriptor, a percentage, or some other alphanumeric symbol. Of particular interest in this process are the integrity of the course grades and where the responsibility should lie for assuring that integrity. Although a transcript may be accompanied by additional information set out in a 
diploma supplement, graduation statement or professional portfolio, the transcript is often taken as the definitive record of validated achievement, course by course. The full transcript reveals the highs, lows and patterns of performance across the degree program and these results feed into informed decisions made by third parties. The content of transcripts and their proper interpretation are especially important in the years immediately following graduation. Clearly, the integrity of course grades has to be a high priority.

\section{Two angles on the issue of academic authority}

In Hill's (2010) overview of the issue, he identified aspects of different North American and wider international manifestations of the tension. Some of these are strongly represented in certain national or international contexts or academic communities, but are almost entirely absent from others. Putting to one side geographical or cultural distributions and histories, Hill's list included: the legal or ethical admissibility for an institution to override grading decisions made by individual academics; the right of academic institutions to act in order to uphold 'institutional' academic standards; the legitimacy of the grounds to which administrators appeal for changing a professor's grades; the role of grades and grading as elements of the power relationship between academic teachers and learners; the desirability of transparency in grading and its implications for finding a balance between course-based standards and systemic standards; and the connection between academic freedom and accountability to various stakeholders. These illustrate the complexity of the tussle between academic autonomy and institutional authority as to who should have the final say in grades.

Notably unexplored in Hill's article is a fundamental issue: the purpose of grading and how it should be carried out. What are course grades supposed to represent? In an ideal situation, what properties should they possess? What exactly is meant by a 'standard' anyway? Tackling the problem as one concerned primarily with relative authority runs the risk of arriving at a resolution which is difficult to apply in practice. The line of development explored below starts at the opposite end, namely, with setting up the central problem as the delineation and characterisation of the desirable 'quality' of grades. It then presents the case for a particular way forward. In this way, the respective rights of the different parties are subordinated to the issue to be addressed.

Brown's (2010) article had a different starting point. Focusing on the situation in England, he discussed in some detail the findings of five reviews of academic standards carried out since the mid-1980s. He analysed the roles played by external examiners, quality assurance agencies and other bodies with strong interests in the quality of higher education. Among the sub-issues which have some bearing on this article were: explicit expectations about the comparability of degrees from different universities; the authority of external examiners to amend marks; the robustness of quality assurance measures for the future and reputation of higher education; the protection of academic judgments without management interference (something 
Brown considers 'one of the cardinal principles', p.135); the potential sensitivity of academic standards to external conditions (including increasing marketisation and competition in higher education, and the role and levels of funding provided by government); and the distance from actual student work at which decisions about the comparability of standards are often made.

This list has a quite different flavour from Hill's. A reasonable inference from Brown's account is that what grades are intended to represent, and therefore what grading as a process is meant to achieve, are fundamental to a discussion of the proper exercise of authority and control for determining and assuring academic standards. Although Brown did not argue this explicitly, his orientation is consistent with the direction developed below, but the latter is not intended to take on board the particular history or current circumstances of the situation in any country in particular, including England.

\section{Grade integrity as the goal}

Grade integrity as a concept was introduced in an article by Sadler (2009), with one aspect of it, namely fidelity, subsequently elaborated in a companion article (Sadler 2010). The full development cannot be summarised here in a few sentences, but the main substantive requirements are that: the variable which forms the object of grading must be confined strictly to achievement; each grade must represent (and therefore be commensurate with) the quality, breadth and depth of the level of achievement a student reaches; grades across courses, programs and higher education institutions must be of comparable academic standing or value; the underlying standards must be calibrated against the requirements or expectations of relevant disciplines, fields or professions; and the standards should be stable over time so that academic and professional qualifications retain their value. Fidelity was separately identified because, in many higher education contexts, certain non-achievements (such as effort and attainment path) have been routinely incorporated into grading decisions. Such elements act as contaminants, making the proper interpretation of grades difficult or impossible. For convenience, fidelity is taken as a given and the other four requirements are referred to collectively as commensurability and comparability. These are what must be attended to.

The course grade is a coded (symbolic) representation of a professional judgment based on multiple sources of evidence (mostly student responses to assessment tasks) and expressed on a ladder of ordered levels. The assessor scrutinises the available evidence, then directly or indirectly draws an inference about the student's achievement. The assignment of the symbol takes place by comparing the observed level with notional performance 'standards' (the rungs on the ladder). The student's level of performance is classified accordingly. If the ladder's rungs could be defined with absolute precision, the grading problem's main sources of uncertainty would be the adequacy of evidence of achievement and the competence and consistency of the assessor. If those were dependable in every way, grading would be a relatively 
simple affair. However, none of the required conditions can be relied on to hold in practice.

The positions of the rungs cannot be defined precisely, and human judgments are rarely perfect. Furthermore, the judgments are not open to checking by an independent method of the type that applies when a tentative medical diagnosis is compared with the results of pathology tests on, say, a tissue sample. Although many approaches to assessment and grading may exhibit some of the trappings of objectivity, they cannot avoid the many subjective judgments that lead up to what might, at the end point, appear to be a purely technical matter. Even when strict procedures, criteria and formulas are applied in a seemingly objective way, the choices of which of those to employ are based on human judgments. The backstop variable is professional consensus among experts using student work as the primary evidence. There is nothing more direct, nothing more fundamental.

Other approaches to grading, including those not yet developed, need to have their validity tested against the best qualitative judgments. The latter constitute what is known formally as the 'criterion variable', a term widely used in statistical regression analysis. Scriven (1972) argued cogently that the only form of objectivity in contexts such as these inheres in collective intersubjectivity, and that is where attention must be focused - on improving intersubjectivity. In developing a strategy for this, starting from scratch is not necessary, because a substantial body of parallel experience exists. This aspect is fleshed out later in this paper but first, some more exploration of basic principles.

\section{The arguments for the extreme positions}

The case for academic autonomy is sometimes taken as self evident. On the occasion that an argument is produced, it typically rests on the qualifications of academics, prevailing socio-legal norms, or both. The qualifications argument is generally along the lines that academics who hold doctoral or equivalent degrees in their respective disciplines and fields are by definition in an authoritative position to judge the quality of students' work in the courses they teach. Additional weight is given when academics design courses and teach them around their specialised knowledge developed through original research and deep immersion in their fields. Academics also associate with relevant colleagues in other universities, keeping them (so it is thought) acquainted with the 'standards' elsewhere. The overall position is that academics are singularly qualified to award grades to their own students.

On the socio-legal norms front, which applies in some countries more than in others, the right to decide grades is interpreted as a fundamental aspect of academic freedom, which has long been a cherished professional norm. At a higher level still, the right to grade without interference has been interpreted in the United States as an expression of free speech, which is a national constitutional right. A well cited case is that of Parate vs. Isibor (1989), a dispute which was referred to the courts. The judge hearing the case ruled that a course grade is a private communication from a professor to a student, and is therefore an utterance protected under the First 
Amendment. (This brief description makes the case sound simpler than it was. In later court cases, some of which were mentioned by Hill 2010, that decision was challenged. No doubt further challenges are to be expected.)

The high qualifications argument is weak on several grounds. During their careers and for a variety of reasons, many academics migrate across the boundaries of a number of disciplines or academic fields and subsequently teach in areas where they have few if any formal qualifications. In addition, the relevance of a doctoral degree to professional competence in curriculum design, pedagogy, assessment and grading is questionable. Many teachers in higher education typically have little formal background in assessment theory and practice, relying instead on their own experience as students and what they have since picked up incidentally but largely uncritically. Copying from what is done elsewhere may be useful, but it is unlikely to be adequate. Even a cursory scan of assessment tasks from a range of institutions shows their quality to be highly variable. Testing for higher-order cognitive and other outcomes requires appropriately designed assessment tasks, and constructing these is a non-trivial exercise.

Moreover, simply knowing about the tasks (as stimuli) throws no light on the quality of student responses to them, the grading procedures, or the 'standards' employed. This leaves untouched the fundamental issue of the integrity of the grades awarded, and what they are intended (or assumed) to represent on official academic transcripts which carry the imprimatur of the awarding institution. This presents a conundrum. On the one hand, expressing grades on an institutional grade scale implies a common metric, invites comparisons in performance to be made across courses, and simplifies the structure of testamurs and transcripts. On the other hand, a wholehearted commitment to the principle of academic autonomy produces no verifiable substantive commonality or comparability in the grades. To that extent, it formalises and legitimates the essential meaninglessness of grades. Logically, the quality assurance problem can have no solution when the commitment to academic freedom is so strong that any move to externalise and monitor academic standards is ruled out of order.

The argument for the institutional prerogative to assure grading standards typically runs along the following lines. Academics, departments and institutions are inescapably accountable to students and to society - as well as to the relevant disciplines and professions - for the standards they employ and the grades they award. It is therefore incumbent upon them to formulate policies and implement procedures that maintain the meaning and worth of grades. Although academics may retain substantial degrees of freedom in the design of assessment plans and the awarding of at least tentative grades, higher education institutions along with external agencies of various types have a vested interest in ensuring that academic and professional standards are in line with societal expectations. Nowadays, an additional commercial incentive is that institutional reputations and rankings are important in attracting and retaining students. Academic qualifications of unknown or poor standing make good reputations difficult to establish or put existing 
reputations at risk. The critical issue is, of course, how an institution conceptualises and exercises its authority in shaping the standards assurance agenda.

The above portrayal of two opposing camps corresponds in broad terms to the autonomy-coercion poles discussed at length by Gaylin and Jennings (1996) in the context of social and political freedom. Their analysis is not fully transferable to the academic freedom debate, but it and similar writings clearly outline the characteristics and the limitations of choosing an adversarial frame of reference in which to debate the issue. If a theoretical resolution is reached, it is likely to be as an intermediate position between the two poles. An alternative process, which starts with a different way of conceptualising the problem, can mark out a solution space that has different dimensions. In particular, suppose academics were to conceptualise their academic professional identity differently, as a true hybrid, instead of purely as individual experts in their disciplines or professions with the sovereign right to decide student grades. Part of that hybrid would be constituted by expertise in the substantive field of scholarship, research and professional practice; the other part would be constituted by expertise as members of the guild of educators in that substantive field. The two parts together are constitutive of the academic as a distinct category or profession. The challenge is to further clarify and develop this identity, with specific reference to how academic freedom can be situated in relation to integrity in grades and grading.

\section{Professionalism and the professional}

If ownership of both the problem and its solution mechanisms became the responsibility of the community of academics acting collectively as a profession rather than as an array of individual experts, a significant dimension would be added. Both ownership and carriage of the solution are legitimate professional activities. In many fields outside higher education, the experience of being a professional is enriched through a strong sense of belonging to a competent and highly skilled community of practitioners, regardless of whether the professional contact with clients is one to one or many to one. The sense of membership of a profession inheres partly in a shared purpose or role in the chosen vocation, and partly in participating in substantive shared activity and discourse. In medicine, for example, patients regularly are invited to seek second or third opinions, as do doctors. However, for academics the sense of being a professional is often partial. On one side, the research component of academic life involves high-level interactions with scholarly peers. They have a common interest in an academic field and constantly monitor, learn from and engage productively in the collective knowledge-generation enterprise in which they are participants. This occurs even when personal face to face contact among researchers is relatively infrequent. The peer review process for evaluating journal article manuscripts, for example, is commonly 'double blind' Neither the researchers nor the reviewers know the identity of the others, the journal editor acting as the main conduit and broker of information. Despite the lack of direct 
communications between reviewers, the sense of a scholarly community - the guild is sustained and reinforced by scholarly interactions.

The pedagogical dimension of academic life is often collegial during the design, development, institutional approval and external accreditation of academic programs and courses. Involvement in teaching teams and engagement in small-scale moderation exercises within a single course is also collegial. When it comes to standards and comparability in grading, collegiality is typically less. The prospect of focused discussion about the fundamental teaching issues relating specifically to assessment, grading and standards opens up collaborative potential for a deepened sense of what it means to be a professional.

The literature on what makes a certain line of work a profession - and what constitutes professionalism - is extensive and varied, but many similarities exist in the basic thrust. The differences are mostly in the detail. At this juncture, two articles by Welie (2004 a, b) are drawn upon for a characterisation of the professional. The summary below has been adapted where appropriate to the context of higher education teaching and set out in list form. A professional is a person who:

- Offers a service of vital importance to the public at large;

- Belongs to a fellowship or guild that holds specialised knowledge and experience for a particular line of work;

- Possesses the fundamental knowledge and expertise to perform complex tasks competently, on demand, and independently of particular others (but not necessarily independently of others altogether);

- Works for the benefit of (learners as) clients, rather than for their own needs or self-interests;

- Enters into (or practices with a status consistent with) a mutual agreement with their colleagues on the one hand and the public on the other in an implicit social contract;

- Shows willingness to review their peers and to submit themselves to peer review, such review being carried out as a matter of course in order to maintain quality of service and thereby eliminate, or at least minimise, the occurrence of untoward events; and

- Recognises that alternative courses of action or service may be equally appropriate or effective in a range of circumstances.

Complementary characteristics are that the profession:

- Is always committed to giving priority to the existential needs and interests of the segment of the public they serve above their own interests, and who in turn are trusted by the public to do so;

- Evaluates itself and is sufficiently self-regulating for the public to see that a member who is judged less than competent is dealt with;

- Keeps its service modalities under continuous review for effectiveness, efficiency and currency; and 
- Has procedures that identify potential conflicts of interest, and guards against and minimises the impact of conflicts between the interests of those they serve and other interests, whether external or their own personal interests.

Professional competence involves being able to do high-level tasks consistently well. Professionalism, on the other hand, entails not only acting in a professional manner but also recognising the constitutive nature of one's profession and keeping oneself updated and calibrated against one's competent peers. Application of these principles to being a professional teacher in higher education involves having relevant interaction with other members of the same profession in all aspects of practice. When it comes to grading, the challenge is simple to state: to arrive at judgments and their summary representations which are or would be consistent with those of peers even when there are no independent sources of data which could substantiate those professional judgments. Clearly, isolationist practices in assessing and grading student achievement are inimical to the development of a guild culture. Shifting the prevailing ethos as it relates to grading achievement starts from a relatively low base of experience in directly pursuing comparability across courses, academic programs and institutions. This may be accompanied by considerable apprehension and insecurity about what moves in that direction might expose and entail.

\section{Isaiah Berlin's concepts of negative and positive liberty}

Clearly, apprehension and insecurity cannot be ignored; they need to be addressed. In this section, certain influential ideas about freedom and liberty expounded by Berlin (a political philosopher) and published in 1969 are applied to the context of academic freedom, grading standards, professionalism and academic identity. Berlin distinguished two concepts of freedom, which he called negative and positive, now commonly referred to as 'freedom from' and 'freedom to'. The difference between these two provides a valuable perspective on meanings for academic freedom and academic autonomy. It also suggests a path through the main tension between a particular conceptualisation of academic freedom and institutional authority. (Although Berlin mostly used the term liberty, he made clear that he regarded liberty and freedom as synonyms. The latter is used here.) Also drawn on are the particularisations of Berlin's ideas by Gaylin and Jennings (1996) as part of their analysis of individualism, autonomy and coercion by the state, corporation, institution or organisation.

Berlin's concept of freedom as negative liberty has to do with 'establishing a zone of privacy and non-interference around each person' (Gaylin \& Jennings, 1996, p.44). It is a person's self-defined region about themselves which:

... appeals to metaphors of space. It wants elbow room, a place of one's own. Negative liberty requires fences and boundaries for protection against outside intruders. It rests on a conflict-ridden and antagonistic picture of social existence, in which each individual struggles with everyone else to control [their] own patch of ground... The rights most closely linked to this sense of autonomy are those that ... protect the individual (p. 44). 
Within their own zones, people can exercise their own faculties and pursue their own lives in their own ways. The zones are 'areas' within which subjects are or 'should be left to do or be' precisely what they are 'able to do or be', without encroachment or coercion by others (Berlin, p.121-122).

In the context of assessment and grading, this corresponds to the interpretation of academic autonomy in which academics in effect assert sovereign right to award marks or grades as they (individually) see fit. They take explicit steps, legal if necessary, to establish and maintain the boundaries of their respective spaces. This, it is hoped, will secure the academic not only from the power of the institution but also to a considerable extent from the student and the public at large. It also carries the obligation on others 'not to trespass, not to intrude uninvited upon the person's zone of privacy and self-determination' (Gaylin \& Jennings, 1996, p.45). '[L]iberty in this sense means liberty from; absence of interference beyond the shifting, but always recognizable, frontier' (Berlin, p.127).

The 'positive' concept of liberty is freedom to. In Berlin's words, it:

... derives from the wish on the part of the individual to be [one's] own master. I wish my life and decisions to depend on myself, not on external forces of whatever kind. I wish to be the instrument of my own, not of other people's acts of will. I wish to be a subject, not an object; to be moved by reasons, by conscious purposes, which are my own, not by causes which affect me, as it were, from outside. I wish to be somebody, not nobody; a doer - deciding, not being decided for, self-directed and not acted upon by external nature or by other [people] as if I were a thing, or an animal, or a slave incapable of playing a human role, that is, of conceiving goals and policies of my own and realising them (p. 131).

Superficially, this may appear to have considerable overlap with negative liberty, but Berlin clarified the distinction. He expanded on the significance of positive liberty by relating it to one's 'real self':

... [T]he real self may be conceived as something wider than the individual (as the term is normally understood) as a social 'whole' of which the individual is an element or aspect: a tribe, a race, a church, a state, the great society of the living and the dead and the yet unborn. This entity is then identified as being the 'true' self which, by imposing its collective, or 'organic', single will upon its recalcitrant members, achieves its own, and therefore their, 'higher' freedom. (p.132)

As Berlin was quick to point out, the last aspect of this characterisation of 'freedom to' can be taken to extremes. That aside, the whole statement nevertheless captures something of considerable value to an analysis of academic freedom. Positive freedom, properly conceived and bounded, fosters a sense of identity that goes with a person-in-relationship, especially a relationship founded on volitional membership of a social whole, of which a profession - as characterised by Welie (2004 a, b) - is an example. It is a relationship of peers which both establishes an identity as a professional and imposes legitimate professional constraints. The two must go together. By definition, there can be no sense of identity unless there are 
corresponding boundaries. This is in marked contrast to the negative concept of liberty, which involves 'self-abnegation in order to attain independence' (Berlin, p.134). The positive concept involves 'self-realization, or total self-identification with a specific principle or ideal in order to attain the selfsame end' (p.134).

In the context of assessment and grading, the identity of self attaches to the principle of collegiality, of guild membership, with one of its purposes being to produce appraisals (and the grades that result) which possess individual and collective integrity. That cannot be achieved under conditions of academic autonomy taken literally, which Berlin characterised as a 'retreat to the inner citadel' (p. 135). Positive liberty involves a different metaphor from no-trespass 'space'. It centres not on control itself, but on the rightful source of control, and the manner in which that control is exercised. Ideally, it represents freedom to practice, to move, to do and to be and remain within parameters which one can be part of negotiating, and which members accept willingly and proudly. 'Autonomy as positive liberty rests on the insight that human self-sufficiency is limited and that freedom often requires the assistance of others' (Gaylin \& Jennings, 1996, p.46).

Within the academy, employment conditions may give the institution formal authority to require performance of a particular kind and at a particular level. These are not founded and administered by and within the profession, although academics and academic unions may be involved in drawing up the employment conditions. Polarising the debate simplistically as individual academic versus higher education institution shows that it has veered away from its roots. A consideration of positive liberty opens the way to a different, collegial route to identity development, less as autonomous experts in a field or discipline, and more as a body of educator-professionals which is collectively responsible for contributing to students' learning (in degree programs), assessing their achievement and reporting their levels of achievement with integrity. It is consistent with collective stewardship over the standards, widely distributed professional responsibility for helping to establish standards, and maintaining the integrity of both the grades and the quality assurance system. Establishment of this role entails equipping academics to expand their horizons to perform tasks which are different in detail but methodologically similar to ones they already know how to do.

In many professions, the volitional element is formalised by some explicit action, such as becoming a registered, licensed or chartered practitioner, with rights to publicise membership openly. Another significant element is a symbolic name, which may be based on a discipline (mathematician, political scientist, musicologist) or a profession (dentist, engineer, accountant), or both. The public is invited to have confidence in the ability of a formal body or agency to vouch for the person's professional capability (competence) and ethics, knowing that infringements by practitioners can precipitate censure, reprimand or even expulsion.

For academics, especially in their educator role, a particular difficulty in identity development is the ambiguity of the title 'academic'. To refer to something as 'academic' is, in many everyday conversations, to imply it is formalistic or theoretical to the point of being out of touch with the real world and perhaps without 
practical purpose or intention. This can have carryover to academics and academic work. At the same time, no other title quite fits. This has implications for both academics as professional educators and for the public's understanding of them. An option that may work but is not explored further here is a formal connection with a professional licensing agency owned and controlled by academics who share the dual conceptualisation of their professional identity, and embraces all domains of academic work including academic grading and achievement standards. Precedents for this exist in other areas, including various professional associations.

\section{The existing platform of practice}

The general pattern is for the responsibility for grading to be distributed across all or nearly all teaching academics. A logical extension of this is that addressing the challenges of commensurability and comparability need to be similarly distributed. This requires systematic engagement of academics in ways that ensure that both the problem and its solution do not become the property of institutional management, or be separated and outsourced to external organisations or testing agencies. This direct approach to standard setting shifts the focus away from 'who controls' towards the problem to be solved. In the process, the respective authorities of academics, institutional management and centralised bodies are resolved not by conciliation or compromise about principles of authority but through jointly developing a solution to the problem of grade integrity.

There is no reason to assume that academic achievement standards shared among higher education educators are less likely to be feasible than performance or service standards in other fields, professions and disciplines. However, except for certain domains, the appraisals academics now make are insufficiently tuned to one another across assessors, contexts and time. To use a more descriptive term, they are largely uncalibrated. The goal of assured achievement standards requires that this be attended to. The detailed logistical arrangements needed to accomplish this are the subject of separate development not reported here. Suffice to say that a substantial proportion of academics in many universities already possess a platform of practice and attitude on which to build, as mentioned earlier in this article. At this point, three of the planks in that platform are reviewed briefly.

\section{Grading to 'standards'}

Academics who have taught for some time have considerable experience in making judgments about student achievement in most if not all courses, undergraduate and graduate. Every course taught provides opportunity and practice. Clearly, academics do not begin each grading event with a blank slate. They proceed as though they have some idea of the 'standards' they intend to apply, even though those standards may be somewhat fuzzy and subject to drift over time. Ideally, academics aim to be fully consistent, fair and open in applying their (individually held) 'standards', and have some appreciation of such hazards as the so-called 'halo' effect. They regularly 
assert that they do not assign grades purely on comparative (norm referenced) grounds, but they do take relativities into account.

Their personal repositories of tacit standards knowledge are developed through previous marking and often some but limited interaction with other academics. For the most part, standards are carried around in academics' heads and drawn on as needed in appraisal situations. The comparative element comes in when academics reset their baselines by first perusing samples of student work, in which case their 'standards' have an existential component. Academics nevertheless retain somewhat enduring knowledge of appropriate standards, of what good work consists of. When grade integrity is the goal, the crucial limitations of these 'standards' are that they are: not necessarily stable over time; relatively inaccessible to students; and either individuated and privately held by academics (single course, single marker) or teambased (single course, multiple markers). They form part of an academic's sense of identity. Given these considerations, it is nevertheless appropriate to treat academics as the obvious candidates for local custodianship of standards that are properly thought through and deprivatised.

\section{Comparability judgments}

Things may be comparable to one another without being alike in detail. Comparability judgments infuse daily life and surface in a host of formal contexts. They are generally handled without any fanfare or conscious effort. The first of two assessment contexts that form part of the platform of practice in comparability involves consensus moderation within a single course when multiple assessors mark student responses to a single assessment task. This situation often arises in courses with large enrolments and courses taught on different campuses. Trial marking of a fixed sample of student works by the various markers is used to fine-tune marking practices and reach agreement on marking standards. This consensus, developed prior to the main marking round, improves the likelihood that subsequent marking and grading will be broadly consistent, regardless of who does the marking. This obviously makes the marks or grades more able to withstand scrutiny in the event of a challenge.

The second context is when academics make or review judgments about grades, standards and grading practices in courses other than those they are currently teaching or have taught previously, and therefore lie outside their own immediate field. Comparability judgments are central to the use of external examiners or auditors; reviews of apparently aberrant distributions of grades by independent panels; the impartial adjudication of student appeals against unfair grades; and the translation of grades from existing courses into those in entirely new fields. Only some of these make use of primary evidence of achievement, but they are all consistent with openness to peer evaluation of grading decisions.

\section{Peer review}

Peer review in the complementary domain of research practice, ethics and formal publication is regarded as the indispensable condition for quality assurance in the 
serious pursuit of knowledge and the dissemination of findings. As an activity, peer review is celebrated and vigorously protected. In many fields, it is firmly established in program accreditation and so forms part of the substance of professional identity. Finally, the orientation and processes of peer review and consensus-seeking activity are consistent with both Welie's characterisation of a profession and Berlin's concept of positive freedom. Given that such collaborative practice is already substantially normalised, a philosophical commitment to autonomy in grading - which specifically excludes grading decisions from similar processes and in so doing elevates autonomy in grading to the status of a defining aspect of academic freedom - is anomalous if not illogical.

\section{Conclusion}

Academic freedom, with academic autonomy as its strongest expression, is often contrasted with institutional authority, with institutional coercion as its strongest expression. The optimum position along the freedom-authority continuum could be debated by first identifying relevant philosophical principles and then applying these to arrive at a solution. The debate needs to be transformed into a goal-driven approach to solving the problem of assuring academic achievement standards rather than an engagement in abstract deliberations. The approach outlined above sets the integrity of course grades as a core item in the debate, and an analysis of the freedom-authority issue is constructed around that. It would involve enlarging and repurposing current moderation methods and developing a system based on peer consensus. Such an approach would be fundamentally in the right direction, fully consistent with the peer-review practices which permeate most other aspects of academic work, and likely to advance a sense of professionalism among academics.

If this line of thinking were adopted, the location and exercise of responsibility for collaboratively setting, controlling and assuring academic standards would reside primarily with the body of academics, but be managed using many of the same processes used in other professions. Evidence that the latter has been largely successful lies in the relatively few occasions in which a higher authority, such as a government instrumentality or specially appointed commission, has had to step in and take control for a period of time. In the grading context, what is needed is that the responsibility for a solution-in-practice be widely distributed, precisely because the problem arises specifically through distributed grading decisions-in-practice. This is a neglected dimension of professionalism in the academy. What is also needed is ownership of both the problem and its solution by academics themselves. By this is meant ownership by the community of academics as a collective, acting collectively as if it were a profession rather than as an assemblage of individuals.

The account of the main features of such a system point to the possibility of a productive partnership in which the respective interests and values both of higher education institutions and of individual academics converge on a range of professionalised processes so that external concerns about standards can be addressed. When practice and thinking are both trapped by national or institutional 
traditions, it is difficult to determine the topography of the decision space within which solutions can be explored or reached. An obvious element running right through this article is that there is little which can be endorsed in current attempts to assure academic standards. There is also an aspirational element: complacency, resignation and despair are rejected. It is time to think not only about what exists, but also about what could be.

\section{References}

Berlin, I., 1969, 'Two concepts of liberty', in Berlin, I. Four essays on liberty pp. 118-172, (London, Oxford University Press).

Brown, R., 2010, 'The current brouhaha about standards in England', Quality in Higher Education, 16(2), pp. 129-137.

Gaylin, W. \& Jennings, B., 1996, The Perversion of Autonomy: The proper use of coercion and constraints in a liberal society (New York, The Free Press).

Hill, D., Online 2010, 'A contentious triangle: Grading and academic freedom in the academy', Higher Education Quarterly, DOI: 10.1111/j.1468-2273.2010.00465.x

Hunt, L. H. (Ed.), 2008, Grade Inflation: Academic standards in higher education (New York, SUNY Press).

Parate v. Isibor, 868 F.2d 821 6th Cir. 1989. (US Federal District Court).

Sadler, D. R., 2009, 'Grade integrity and the representation of academic achievement', Studies in Higher Education, 34(7), pp. 807-826.

Sadler, D. R., 2010, 'Fidelity as a precondition for integrity in grading academic achievement', Assessment and Evaluation in Higher Education, 35(6), pp. 727-743.

Scriven, M., 1972, 'Objectivity and subjectivity in educational research', in Thomas, L. G., (Ed.) Philosophical Redirection of Educational Research: 71st NSSE Yearbook, pp. 94-42, (Chicago: National Society for the Study of Education).

Welie, J. V. M., 2004a, 'Is dentistry a profession? Part 1: Professionalism defined', Journal of the Canadian Dental Association, 70(8), pp. 529-532.

Welie, J. V. M., 2004b, 'Is dentistry a profession? Part 2: The hallmarks of professionalism', Journal of the Canadian Dental Association, 70(9), pp. 599-602.

Brief author bio

D Royce Sadler is Senior Scholar in Assessment and Professor Emeritus in the Griffith Institute for Higher Education, Griffith University, Brisbane. His current research is on grading and academic achievement standards in higher education and assessment that leads to improved learning and student capability. 